American Journal of Biochemistry and Biotechnology 5 (4): 184-188, 2009

ISSN 1553-3468

(C) 2009 Science Publications

\title{
Determination of Precipitation Limit of Zn(II) Ion with (2S)-2-Aminobutanedioic Acid
}

\author{
Fatmir Faiku, Haxhere Faiku, Arben Haziri, Fatbardh Gashi, Naser Troni, \\ Sevdije Govori and Albert Maxhuni \\ Department of Chemistry, Faculty of Natural Sciences, University of Prishtina, \\ Mother Tereza Street 5, 10000 Prishtine, Republic of Kosova
}

\begin{abstract}
Problem statement: In this study we examined the precipitation of $\mathrm{Zn}(\mathrm{II})$ ion in water solutions of $\mathrm{ZnSO}_{4} .7 \mathrm{H}_{2} \mathrm{O} \quad\left(1.10^{-2}\right.$ and $\left.5.10^{-3} \mathrm{~mol} \mathrm{~L}^{-1}\right)$ with $(2 \mathrm{~S})$-2-aminobutanedioic acid $\left(1.10^{-1}\right.$ $1.10^{-3} \mathrm{~mol} \mathrm{~L}^{-1}$ ) in constant ionic strength of $0.6 \mathrm{~mol} \mathrm{~L}^{-1} \mathrm{NaCl}$. We have determined the concentration region where we have found the clear solution and solid phase. The solid phase is analyzed by IR spectroscopy. Approach: From precipitation diagrams of zinc with (2S)-2-aminobutanedioic acid in ionic force $0.6 \mathrm{~mol} \mathrm{~L} \mathrm{~L}^{-1} \mathrm{NaCl}$, we have found that during decreasing the concentration (2S)-2aminobutanedioic acid in case of constant concentration of $\mathrm{Zn}$ (II) the limit of precipitation is shifted to lower values of $\mathrm{pH}$. Results: Also from precipitation diagrams we can see that when the concentration of zinc increases, in case of constant concentration of (2S)-2-aminobutanedioic acid the limit of precipitation will shift at lower values of $\mathrm{pH}$. Conclusion: From the IR spectroscopic analysis we can conclude that $\mathrm{Zn}$ (II) ion has reacted with (2S)-2-aminobutanedioic acid.
\end{abstract}

Key words: Precipitation, $\mathrm{Zn}$ (II) Ion, (2S)-2-aminobutanedioic acid, IR spectroscopy

\section{INTRODUCTION}

The oceans and seas water contain metals also zinc and other helate ligands in normal quantity but sometimes depends on pollution they can contain high level of this metals and ligands. We can find complexes which are not so stable with different inorganic ligands, as example chloride ions and complexes which are stable formed from metals and helate ligands from organic maters or formed from polluted water ${ }^{[1]}$.

Toxic metals as zinc are considered as non toxic when it is complexes with helate ligands. Water organisms (fish's) can eat these complexes, but it is not believed that these kinds of compounds can entry to the nutritative chain. But this should investigate very carefully in each case ${ }^{[1]}$.

Taking $\mathrm{Pb}, \mathrm{Zn}$ and $\mathrm{Cd}$ not helated and accumulation of these from planktons and fishes are described from researchers ${ }^{[2]}$. The quantity of this metals accumulated in fishes depend on sort of fishes and increase if the $\mathrm{pH}$ of environment decrease ${ }^{[2]}$.

From investigation, on human population, now it is known that these metals can cause negative effects on organisms.

Gorell and collaborators ${ }^{[3]}$ have investigated the population with 50 years old and they have found that this metals especially zinc are very danger factors on the Parkinson disease.

Some studies which are done to some Japanese worker it is found that $\mathrm{Cu}$ and $\mathrm{Zn}$ have different neurological effect compared to the $\mathrm{Pb}^{[4,5]}$.

The Aim of this work was to investigate the condition for removing of $\mathrm{Zn}$ cation through precipitation method with (2S)-2-aminobutanedioic acid as ligand.

\section{MATERIALS AND METHODS}

In this study we used: $\mathrm{ZnSO}_{4} \cdot 7 \mathrm{H}_{2} \mathrm{O}$, (2S)-2aminobutanedioic acid as a ligand, sodium hydroxide and sodium chloride. For this investigation we have prepared some concentrated soluble which are stored on glass bottles in room temperature. Diluted solution we have prepared fresh for each series of precipitated systems. The precipitated systems are prepared using methods from Tezhak and collaborators ${ }^{[6]}$.

Precipitated system $\mathrm{ZnSO}_{4} .7 \mathrm{H}_{2} \mathrm{O}$ with (2S)-2aminobutanedioic acid is investigated in the long region of concentration with ionic force of $\mathrm{NaCl} 0.6 \mathrm{~mol} \mathrm{~L}^{-1}$.

As example, one series it's prepared in this way:

- The solution was added in two line of test-tube. In the first line of test tubes is added the solution of

Corresponding Author: Fatmir Faiku, Department of Chemistry, Faculty of Natural Sciences, University of Prishtina, Mother Tereza Street 5, 10000 Prishtinë, Republic of Kosova 
$\mathrm{ZnSO}_{4} \cdot 7 \mathrm{H}_{2} \mathrm{O}$ with determinate concentration (as example $0.1 \mathrm{~mol} \mathrm{~L}^{-1}$ ). In second line of test tube we have added the (2S)-2-aminobutanedioic acid solution with determined concentration (as example $1 \mathrm{~mol} \mathrm{~L}^{-1}$ ). The second line of test tube we have added also the $\mathrm{NaCl}$ in that way that ionic force to be $0.6 \mathrm{~mol} \mathrm{~L}^{-1}$. After that we added the solution of $\mathrm{NaOH}$ to increase the $\mathrm{pH}$ value. The total volume in each test tube should be $10 \mathrm{~mL}$. The differences till $10 \mathrm{~mL}$ we have fill with distillate water

- Contain of solution to the first line of test tube was added to the solution of second test tube (7 times per $20 \mathrm{sec})$. All the concentration is calculated on the total volume after mixing that means at $10 \mathrm{~mL}$

The systems after mixed are stored on thermostat for $24 \mathrm{~h}$ in the temperature $25^{\circ}$. To determine the precipitated diagrams, if the concentration of $\mathrm{Zn}$ ions stays unchanged, we have to change the concentration of (2S)-2-aminobutanedioic acid. For that we used three deferent concentration of (2S)-2aminobutanedioic acid for one concentration of $\mathrm{Zn}$ ion. We used concentration of (2S)-2aminobutanedioic acid $1.10^{-1}, 1.10^{-2}$ and $1.10^{-3} \mathrm{~mol} \mathrm{~L}^{-1}$ for each concentration of $\mathrm{Zn}$ (II). For zinc ion we used two concentration $1.10^{-2}$ and $5.10^{-3} \mathrm{~mol} \mathrm{~L}^{-1}$. All of these systems we added solution of $\mathrm{NaCl}$ in that way that ionic force to be $0.6 \mathrm{~mol} \mathrm{~L}^{-1}$. Also we added the $\mathrm{NaOH}$ to change the $\mathrm{pH}$ values. Precipitated systems are monitories after $24 \mathrm{~h}$. It is determinate the concentration which cause the difference between clear solution and precipitation. Then it is measured the $\mathrm{pH}$ value on the top of precipitate with $\mathrm{pH}$ meter, Metrohm"

- $\quad$ Some precipitates are prepared in large quantity for quantity analysis. Systems have stored in thermostat for $24 \mathrm{~h}$ in the temperature of $25^{\circ}$, then the $\mathrm{pH}$ value is measured on the top of precipitate. These systems are filtered (filtered paper with blue line) and are dried on the air. We used the IR spectre to characterize and to find the presence of organic components to this precipitate

\section{RESULTS}

Precipitation of zinc(II) with (2S)-2aminobutanedioic acid was investigated to concentration of zinc $1.10^{-2}$ and $5.10^{-3} \mathrm{~mol} \mathrm{~L}^{-1}$ with different concentration of (2S)-2-aminobutanedioic acid $\left(1.10^{-1}, 1.10^{-2}\right.$ and $\left.1.10^{-3} \mathrm{~mol} \mathrm{~L}^{-1}\right)$. We have added the solution of $\mathrm{NaCl}$ because we want that general ionic force to be $0.6 \mathrm{~mol} \mathrm{~L}^{-1}$. In this mixture we added the
$\mathrm{NaOH}$ solution in that way that $\mathrm{pH}$ increase continually and from here to find at which $\mathrm{pH}$ value it precipitate.

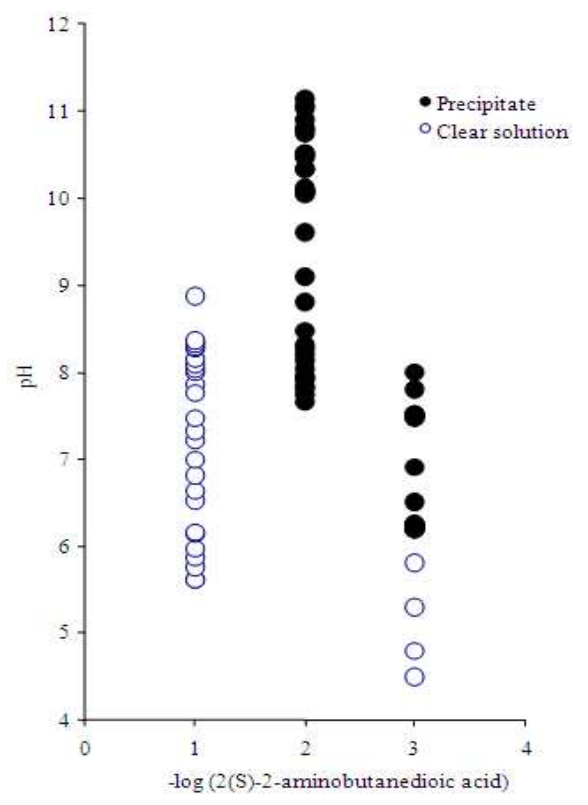

Fig. 1: Precipitate diagram of $\mathrm{Zn}$ (II) in concentration $1.10^{-2}$ mol L ${ }^{-1}$ with (2S)-2-aminobutanedioic acid

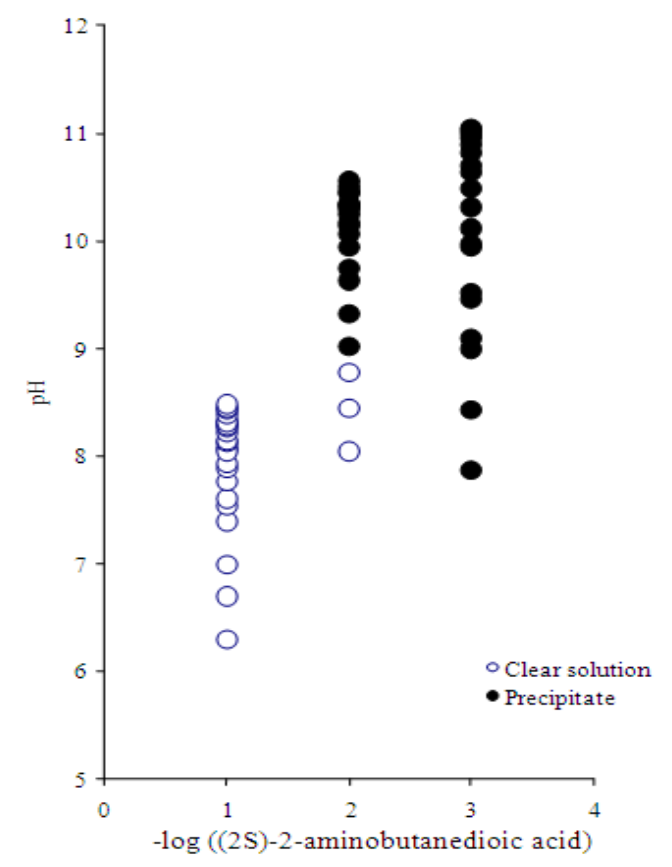

Fig. 2: Precipitate diagram of $\mathrm{Zn}$ (II) in concentration $5.10^{-3} \mathrm{~mol} \mathrm{~L}^{-1}$ with (2S)-2-aminobutanedioic acid 
We have found that diagrams have not changed after a long stored and for that the time of $24 \mathrm{~h}$ it's approved as time of achieved the equilibrium. To analyze the precipitate some of test tubes are filtered and are dried in the room temperature. These precipitate are characterized with IR spectra (Fig. 4 and 5). We have obtained also the IR spectra of (2S)-2aminobutanedioic acid (Fig. 3).

\section{DISCUSSION}

From the precipitation diagram (Fig. 1) of zinc (II) with (2S)-2-aminobutanedioic acid we can see that when concentration of zinc is $1.10^{-2} \mathrm{~mol} \mathrm{~L}^{-1}$ and concentration of (2S)-2-aminobutanedioic acid $1.10^{-1}$ mol L ${ }^{-1}$ we have not the precipitate, but the precipitate start when the concentration of (2S)-2- aminobutanedioic acid is $1.10^{-2}$ and $1.10^{-3} \mathrm{~mol} \mathrm{~L}^{-1}$ at the value of $\mathrm{pH}=7.66$ respectively 6.18 .

From the precipitation diagram (Fig. 2) of zinc(II) with (2S)-2-aminobutanedioic acid we can see that when concentration of zinc is $5.10^{-3} \mathrm{~mol} \mathrm{~L}^{-1}$ and concentration of (2S)-2-aminobutanedioic acid $1.10^{-1} \mathrm{~mol} \mathrm{~L}^{-1}$ we have not the precipitate, but the precipitate start when the concentration of (2S)-2aminobutanedioic acid is $1.10^{-2}$ and $1.10^{-3} \mathrm{~mol} \mathrm{~L}^{-1}$ at the value of $\mathrm{pH}=9.02$ respectively 7.87 .

From precipitation diagrams (Fig. 1 and 2) of zinc with (2S)-2-aminobutanedioic acid in ionic force $0.6 \mathrm{~mol} \mathrm{~L}^{-1} \mathrm{NaCl}$, we have found that during decreasing the concentration (2S)-2-aminobutanedioic acid the limit of precipitation I s shifted to lower values of $\mathrm{pH}$ (Fig. 1 and 2).

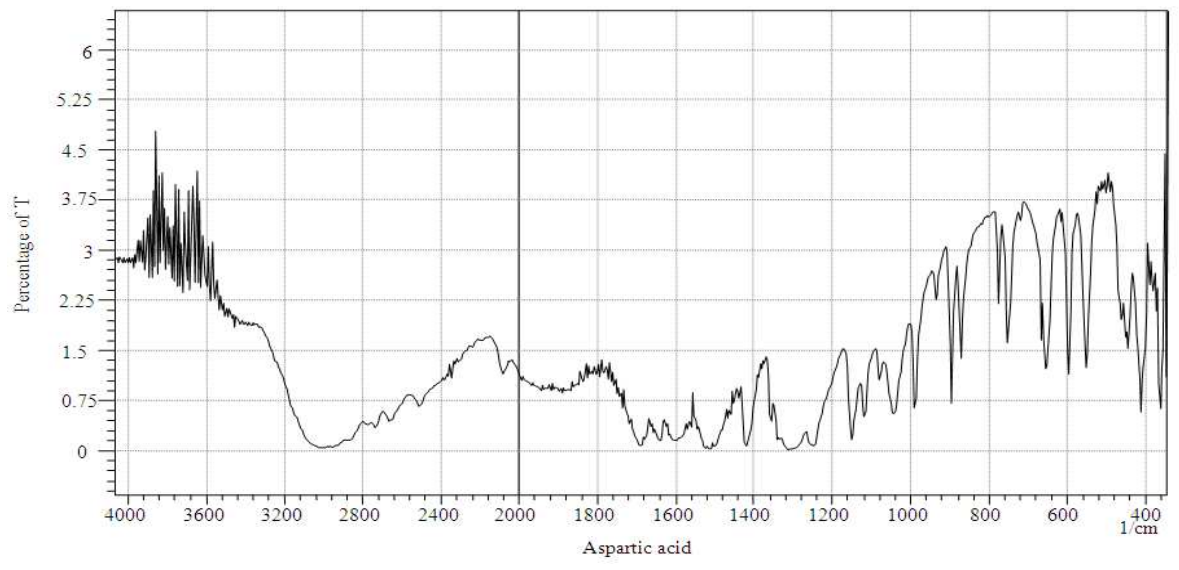

Fig. 3: IR spectra of (2S)-2-aminobutanedioic acid

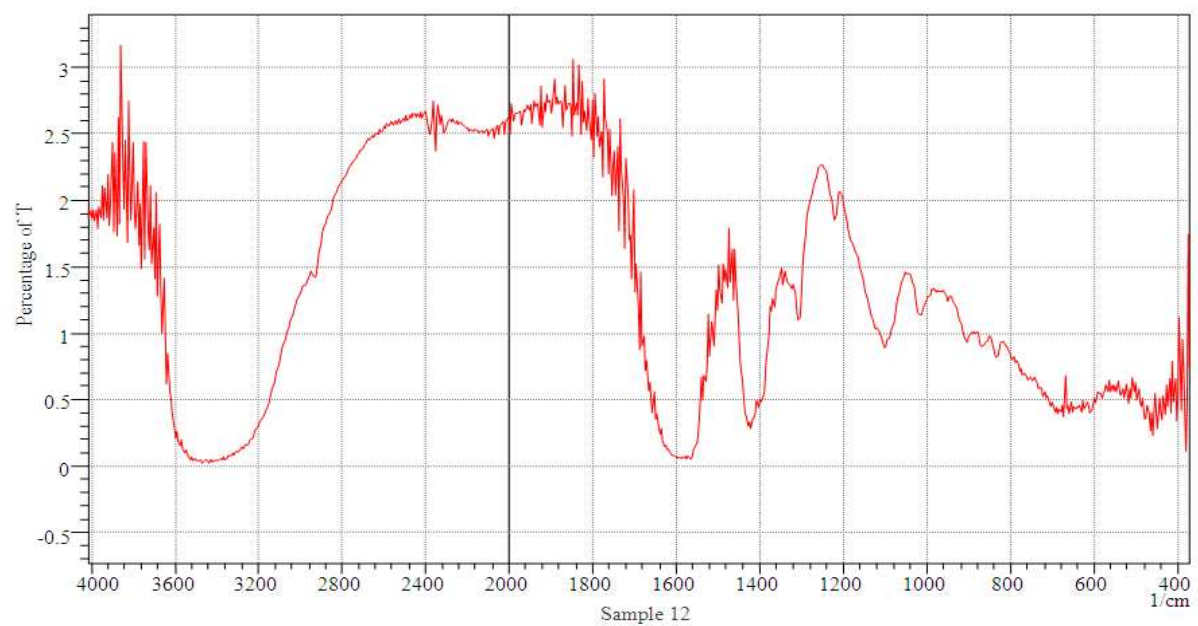

Fig. 4: IR spectra of precipitate which is formed after interaction of $\mathrm{Zn}(\mathrm{II})$ with (2S)-2-aminobutanedioic acid: $\mathrm{c}($ zinc $(\mathrm{II}))=5.10^{-3} \mathrm{~mol} \mathrm{~L}^{-1} ; \mathrm{c}((2 \mathrm{~S})-2$-aminobutanedioic acid $)=1.10^{-3} \mathrm{~mol} \mathrm{~L}^{-1} ; \mathrm{pH}=7.87$ 


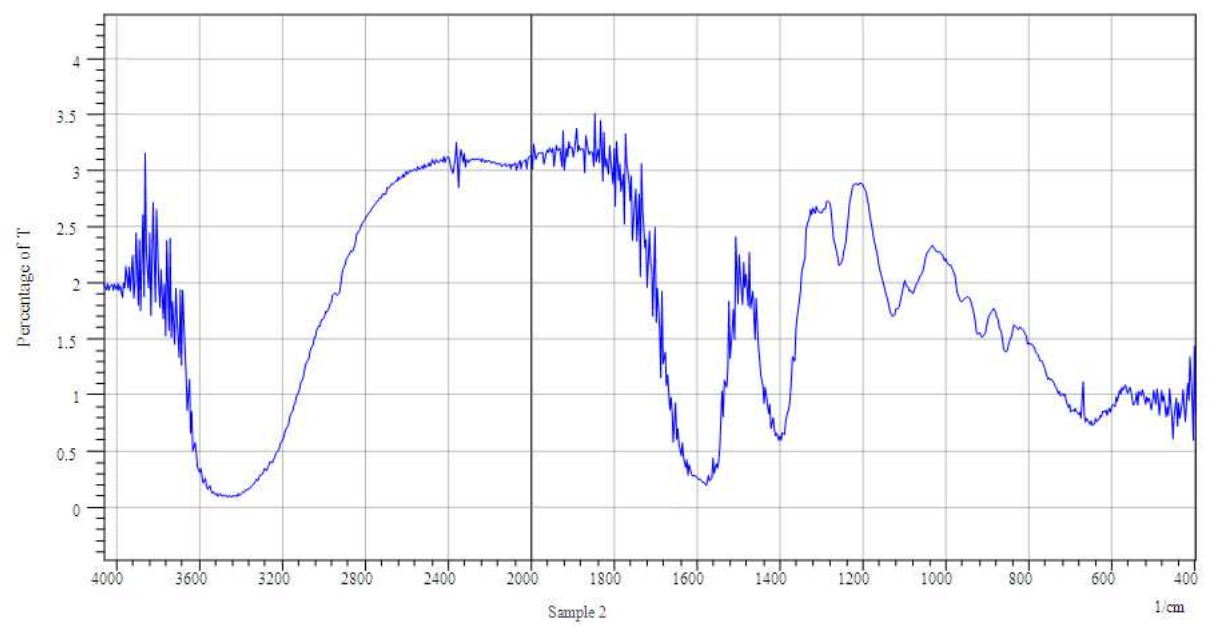

Fig. 5: IR spectra of precipitate which is formed after interaction of $\mathrm{Zn}(\mathrm{II})$ with (2S)-2-aminobutanedioic acid: $\mathrm{c}(\mathrm{zinc}(\mathrm{II}))=1.10^{-2} \mathrm{~mol} \mathrm{~L}^{-1} ; \mathrm{c}((2 \mathrm{~S})-2$-aminobutanedioic acid $)=1.10^{-2} \mathrm{~mol} \mathrm{~L}^{-1} ; \mathrm{pH}=9.02$

Comparing the IR spectres we can conclude that we have interaction between zinc and (2S)-2aminobutanedioic acid. To the (2S)-2-aminobutanedioic acid IR spectra (Fig. 3.) we see the peaks at $1710 \mathrm{~cm}^{-1}$ which characterize the carboxyl group. At solid phase this peaks are shifted at lower values, $1600 \mathrm{~cm}^{-1}$ (Fig. 4 and 5). This tells us for the interaction of zinc with (2S)-2-aminobutanedioic acid.

\section{CONCLUSION}

From the precipitation diagrams (Fig. and 2) of zinc(II) with (2S)-2-aminobutanedioic acid we can see that when concentration of zinc is $1.10^{-2}$ and $5.10^{-3} \mathrm{~mol} \mathrm{~L} \mathrm{~L}^{-1}$ and concentration of (2S)-2aminobutanedioic acid $1.10^{-1} \mathrm{~mol} \mathrm{~L} \mathrm{~L}^{-1}$, zinc not form precipitate. The precipitation of zinc with (2S)-2aminobutanedioic acid starts with decreasing of concentration of (2S)-2-aminobutanedioic acid in $1.10^{-2}$ and $1.10^{-3} \mathrm{~mol} \mathrm{~L}^{-1}$ and in this case the limit of precipitation shifted in low values of $\mathrm{pH}$ in case of decreasing of concentration of (2S)-2-aminobutanedioic acid. Also from precipitation diagrams we can see that when the concentration of zinc increase, in case of constant concentration of (2S)-2-aminobutanedioic acid the limit of precipitation will shift at lower values of $\mathrm{pH}$.

Solid precipitates are analyzed by IR spectrophotometer and the IR spectra which we have obtained are compared with IR spectra of (2S)-2aminobutanedioic acid. From the IR spectra of solid phase and IR spectre of (2S)-2-aminobutanedioic acid we can see that they are not same. From the IR spectra of solid phase we can conclude that zinc can react with (2S)-2-aminobutanedioic acid. The IR spectra of (2S)2-aminobutanedioic acid and precipitates are not same if we compare in the form and in the intensity of peaks. This investigation of interaction between (2S)-2aminobutanedioic acid and zinc are very interesting for environmental aspects and for that we have investigate the precipitate diagram of zinc with (2S)-2aminobutanedioic acid.

\section{ACKNOWLEDGMENT}

The researchers acknowledge the financial support received from the University of Prishtina, Kosova.

\section{REFERENCES}

1. Ibanez, J.G., M. Hernandez-Esparza, C. DoriaSerrano, A. Fregoso-Infante and M.M. Singh, 2007. Environmental Chemistry. Springer Verlag, ISBN: 03874949 28, pp: 238.

2. Mathis, B.J. and N.R. Kevern, 1975. Distribution of mercury, cadmium, lead and thallium in a Eutrophic Lake. Hydrobiology, 46: 207-222. ISSN: 1573-5117.

3. Gorell, J.M., C.C. Johnson, B.A. Rybicki, E.L. Peterson and G.X. Kortsha et al., 1997. Occupational exposures to metals as risk factors for Parkinson's disease. Neurology, 48: 650-658.

4 Araki, S., K. Murata, E. Uchida, H. Aono, H. Ozawa, 1993. Radial and median nerve conduction velocities in workers exposed to lead, copper, and zinc: A follow-up study for 2 years. Environ. Res., 61: 308-316. DOI: 10.1006/ENRS.1993.1075 
5. Araki, S., K. Murata, K. Yokoyama and E. Uchida, 1992. Auditory event-related potential (P300) in relation to peripheral nerve conduction in workers exposed to lead, zinc, and copper: Effects of lead on cognitive function and central nervous system. Am. J. Ind. Med., 21: 539-547. DOI: 10.1002/ajim.4700210409
6. Tezak, B., E. Matijevic and K. Schulz, 1951. Coagulation of hydrophobic sols in statu nascendi. I. Determination of coagulation values. J. Phys. Colloid Chem., 55: 1557-1567. DOI: $10.1021 / \mathrm{j} 150492 \mathrm{a} 016$ 